\title{
Foraminíferos e Bioestratigrafia: uma abordagem didática
}

\author{
Geise de Santana dos Anjos Zerfass \\ PRH/ANP-12, Progr. Pós-Graduação em Geociências \\ Instituto de Geociências - Univ. Federal do Rio Grande do Sul \\ geise.anjos@ufrgs.br
}

Edilma de Jesus Andrade

Progr. Pós-Graduação em Geociências

Instituto de Geociências - Univ. Federal da Bahia

edilma@phoenix.org.br

\begin{abstract}
RESUMO O Princípio da Sucessão Faunística foi o primeiro passo para a aplicação da paleontologia na resolução de problemas estratigráficos pela utilização de fósseis para zoneamento e correlação de estratos. A aplicação teve início com observações de macrofósseis em estratos marinhos por naturalistas, geólogos e engenheiros, na primeira metade do século XX, mas o maior desenvolvimento da ferramenta decorreu do estudo dos microfósseis, como os foraminíferos, um dos grupos mais pesquisados. A aplicação direta na indústria do petróleo revolucionou o conhecimento da bioestratigrafia do Cenozóico. A difusão e o aperfeiçoamento da bioestratigrafia a partir da segunda metade do século XIX decorreu da sua aplicação na indústria do petróleo. Os avanços recentes da bioestratigrafia incluem utilização integrada de diversos grupos taxonômicos bem como a associação com diversas técnicas como a estratigrafia de seqüências e a sísmica. Para aplicação eficaz da bioestratigrafia é importante o conhecimento das relações filogenéticas e dos fatores limitantes à distribuição dos organismos além de aspectos tafonômicos que condicionam distribuição dos restos fósseis. Esse trabalho apresenta, de maneira didática, aspectos históricos e a base conceitual da bioestratigrafia com base em foraminíferos, e sugestões de atividades para a fixação dos conceitos.
\end{abstract}

\section{Palavras-Chave: Fósseis - Idade relativa - Bioestratigrafia - Foraminíferos}

\begin{abstract}
Foraminifera and biostratigraphy: A teaching approach. The Principle of the Faunistic Succession was the first step to the application of paleontology for the resolution of stratigraphic problems by the use of fossils for strata zoning and correlation. The application of paleontology to solve stratigraphic problems began with the observation of macrofossils in marine strata by naturalists, geologists and engineers in the first half of the $19^{\text {th }}$ century. However, the major advances were a result of the study of microfossils, which include the foraminifera, one of the more studied groups. Their direct application in the petroleum industry has revolutionized the knowledge of the Cenozoic biostratigraphy. The diffusion and improvement of biostratigraphy from the second half of the $19^{\text {th }}$ century resulted from the petroleum industry. The recent advances of biostratigraphy include the integrated use of diverse taxonomic groups as well as the association with techniques such as sequence stratigraphy and seismic. To efficiently apply biostratigraphy is important to know the phylogenetic relationship between organisms, limiting factor of their distribution and taphonomic aspects that influence theirs fossils remains distribution and preservation. The purposes of this work are present, in a didactic approach, historical aspects and theoretical bases of biostratigraphy using foraminifera, and suggested exercises for teaching the concepts.
\end{abstract}

Keywords: Fossils - Relative age - biostratigraphy - foraminifera 


\section{Introdução}

O conhecimento sobre a evolução da vida, principal objeto de estudo da paleontologia, associado ao conhecimento geológico constituem uma poderosa ferramenta para a reconstrução do passado do nosso planeta, com aplicações práticas entre as quais a exploração de recursos minerais tais como o petróleo. Deste modo, a bioestratigrafia se insere no ensino das geociências como uma disciplina integradora, levando o aluno a construir elos entre os conhecimentos adquiridos em diversas disciplinas tais como a geotectônica e a geologia histórica para o entendimento de eventos geológicos de diversas magnitudes, além de propiciar uma visão do impacto das variações ambientais, como as alterações na temperatura global e as variações do nível do mar, nos ecossistemas ao longo do tempo geológico.

A aplicação da paleontologia na resolução de problemas estratigráficos através da utilização de fósseis para o zoneamento e correlação de estratos teve início a partir das observações de macrofósseis em estratos marinhos por naturalistas, geólogos e engenheiros, na primeira metade do século 19. Entretanto, o maior desenvolvimento desta ferramenta decorreu do estudo dos microfósseis, dentre os quais destacam-se os foraminíferos, que representam um dos grupos mais pesquisados, e cuja aplicação direta na indústria do petróleo revolucionou o conhecimento da bioestratigrafia.

O primeiro registro de foraminíferos fósseis (Nummulites gizehensis, Forskal) foi relatado por Heródoto (484 - 420 a.C.) em blocos de calcário utilizados pelos egípcios durante a construção das pirâmides em Gizé, os quais foram descritos na época como lentilhas petrificadas que teriam sido utilizadas na alimentação dos escravos que trabalharam na construção das pirâmides. Posteriormente, Estrabão (54 a.C. - 24 d.C.) argumentou que essa interpretação deveria estar equivocada uma vez que os referidos "artefatos" eram encontrados com freqüência em outros lugares (Yassini \& Jones 1995, Molina 2004).

Muitas idéias errôneas foram difundidas pela Escola Aristotélica de modo que não apenas os Nummulites, mas diversos outros grupos de macroforaminíferos ${ }^{1}$ foram interpretados como moedas ou outros objetos petrificados até a Idade Média (Lipps 1981, Molina 2004). Em 1665, Robert Hooke

\footnotetext{
${ }^{1}$ Organismos unicelulares como os demais foraminíferos, porém de grandes dimensões e cuja principal característica é a complexidade da estrutura interna da carapaça.
}

em sua obra "Micrographia", fez a primeira descrição e ilustração de um microforaminífero (Ammonia beccarii Brünnich). d'Orbigny, em 1826, classificou os foraminíferos como pequenos cefalópodos e, posteriormente, cunhou o nome pelo qual esses organismos são conhecidos até os dias atuais. Entretanto, apenas em 1835 Felix du Jardin demonstrou a natureza unicelular dos foraminíferos e criou o termo Rizopoda, e assim esses organismos passaram a ser classificados como protozoários (Yassini \& Jones 1995, Molina 2004). Em 1862 o geólogo e paleontólogo A.E. Reuss propôs a primeira classificação moderna dos foraminíferos com base nos caracteres morfológicos da testa (Arenillas, 2004).

Com o reconhecimento do valor estratigráfico dos foraminíferos, em meados do século 19 , os estudos se intensificaram e estes microfósseis, especialmente os planctônicos, passaram a ser considerados excelentes fósseis-guias devido ao seu alto potencial de preservação no registro geológico, abundância (alguns gramas de sedimentos do fundo oceânico podem conter até milhares de exemplares), rápida taxa de evolução e ampla distribuição geográfica.

\subsection{Foraminíferos - Generalidades}

Os foraminíferos são eucariontes unicelulares heterotróficos, pertencentes ao Reino Protoctista, Filo Granuloreticulosa, Classe Foraminífera (Loeblich \& Tappan 1992, Sen Gupta 1999). Esses organismos são globalmente abundantes e ocorrem desde a transição entre o continente e a plataforma continental até a planície hadal (Seyve 1990, Arenillas 2004).

Os foraminíferos secretam uma carapaça denominada testa, de composição calcária (calcítica ou aragonítica) ou a constroem a partir da aglutinação de partículas minerais, biogênicas ou, mais raramente, esta testa é de composição orgânica ou silicosa. Essa estrutura permitiu ao grupo marcar a sua presença no registro fossilífero desde o Cambriano (Pawlowski et al. 2003).

A testa é formada por uma ou várias câmaras que se intercomunicam através de uma ou mais aberturas chamadas forâmens. As espécies multiloculares, cuja testa é constituída por várias câmaras iniciam seu ciclo de vida, assim como as uniloculares, com uma única câmara denominada prolóculo. Os caracteres morfológicos da testa constituem a base para a distinção entre os taxa ${ }^{2}$

\footnotetext{
2 Plural de táxon.
} 
na classificação dos foraminíferos, a qual utiliza os caracteres morfológicos da testa como critério dentre as quais a composição da parede, a forma, o arranjo e número de câmaras, as linhas de sutura, o número e a posição da(s) abertura(s) e a ornamentação (Fig. 1). O crescimento da testa

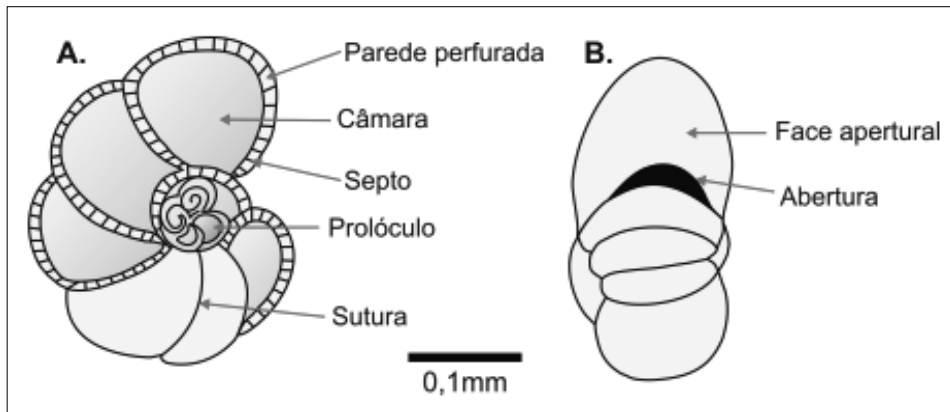

Figura 1 - Morfologia básica para a classificação dos foraminíferos. A. vista espiral em seção longitudinal parcial, mostrando a estrutura interna e morfologia externa. B. Vista lateral mostrando a abertura primária sedimentos (infaunais), ou ainda fixos (sésseis) a diversos tipos de substratos mediante a cimentação carbonática ou da alta viscosidade da camada ectoplamática (Seyve 1990, Arenillas 2004).

A evolução dos primeiros foraminíferos é vista como um processo gradual de mudança na composição e estrutura da parede da testa, iniciando com formas uniloculares de parede orgânica simples que evoluíram para formas com parede aglutinada e, posteriormente para formas multiloculares $(\mathrm{Pa}-$ wlowski et al. 2003). Os primeiros foraminíferos surgiram na base do Cambriano e constituíam formas aglutinantes, sendo que o mais antigo foraminífero já registrado, Platysolenites antiquissimus (Eichwald), surgiu entre 545 e $540 \mathrm{Ma}$ (Lipps \& Rozanov 1996). Posteriormente, no Siluriano, surgiram os foraminíferos bentônicos de parede calcária pode ser contínuo, originando formas uniloculares, ou pode ocorrer em estágios, originando formas multiloculares, cujas formas jovens ou neânicas geralmente têm aparência diferente das formas adultas (Seyve 1990, Arenillas 2004). O tamanho médio das testas dos foraminíferos varia entre 100 $\mu \mathrm{m}$ e $1000 \mu \mathrm{m}$, sendo encontradas exceções de até alguns centímetros de comprimento.

A parte orgânica dos foraminíferos consiste de uma massa protoplasmática que contém um ou mais núcleos e é limitada por uma membrana. A porção do protoplasma que se encontra dentro da carapaça é chamada de endoplasma, e a porção externa, ectoplasma. No ectoplasma se dá a interação entre o organismo e o ambiente através de prolongamentos filamentosos e longos chamados pseudópodos, que possuem função locomotora, de fixação e de captura de alimento (Boltovskoy 1965, Arenillas 2004).

Em linhas gerais, os foraminíferos se alimentam de diatomáceas, algas, bactérias, partículas orgânicas ou larvas de metazoários, constituindo grupos detritívoros, suspensívoros, bacteriófagos ou onívoros. Ao mesmo tempo, algumas formas possuem simbiontes fotossintéticos como forma de complementar a alimentação (Arenillas 2004). Em termos de hábito, os foraminíferos podem ser planctônicos ou bentônicos. Os planctônicos vivem na massa d'água enquanto os bentônicos vivem no fundo marinho. Estes últimos podem ser formas móveis (vágeis) ou viver sobre (epifaunais) ou dentro dos e, no final do Triásico, os foraminíferos planctônicos (Arenillas 2004).

\section{Bioestratigrafia}

\subsection{Histórico}

Poucas áreas da ciência tiveram um único homem reconhecido como seu fundador. Entre elas está a bioestratigrafia, cujos fundamentos foram lançados por William Smith (1769-1839), um engenheiro e construtor de canais inglês. Por volta de 1796, Smith compreendeu que um determinado estrato é sempre encontrado na mesma ordem de superposição e contem os mesmos fósseis peculiares. A Lei da Superposição ${ }^{3}$ de Nicolas Steno já havia sido formulada desde 1669, mas provavelmente Smith nunca ouvira falar em Steno (Hancock 1977). Em 1815, os resultados de Smith foram publicados acompanhando seu mapa geológico da Inglaterra, o qual utilizou pela primeira vez o conteúdo fossilífero como ferramenta para mapear as rochas, enfatizando a sua posição estratigráfica. Deste modo, Smith introduziu o Princípio da Sucessão Faunística, o qual postula que diferentes unidades de rochas sedimentares superpostas contêm diferentes assembléias fósseis (Hancock 1977).

\footnotetext{
${ }^{3}$ Em uma sucessão não-deformada de rochas sedimentares, cada camada é mais antiga que a sobrejacente e mais jovem que a subjacente.
} 
Em junho de 1816, Smith publicou a primeira parte da sua obra "Strata identified by organized fossils, containing prints on coloured paper of the most characteristic specimens in each stratum" (1816-1819), nunca concluída. Em diversos aspectos este trabalho contém o mais completo relato das observações do autor, porém, o que mais se aproxima de um sumário geral de sua obra é "Stratigraphical system of organized fossils", publicado em 1817, onde ficou claro que o autor havia reconhecido dois princípios importantes: o primeiro, que um único pacote litológico pode ser subdividido de acordo com a distribuição dos seus fósseis, e o segundo, que os fósseis de uma mesma fácies com diferentes idades podem apresentar semelhanças (Hancock 1977).

William Smith foi o primeiro a reconhecer a importância dos fósseis na investigação das rochas sedimentares, tendo observado que a seqüência dos fósseis, em um dado registro estratigráfico, segue uma ordem específica que pode ser encontrada em estratos aflorantes em outras localidades, possibilitando a correlação (Hancock 1977). Após a demonstração de Smith da validade do Princípio da Sucessão Faunística, em seu mapa geológico da Inglaterra, o conteúdo fossilífero das sucessões sedimentares passou a ser utilizado como um critério para a subdivisão do registro geológico.

Embora o Princípio da Sucessão Faunística tenha aberto grandes precedentes para o desenvolvimento futuro da bioestratigrafia, era necessário ter uma visão mais independente das sucessões fossilíferas. William Smith compreendeu que as rochas podem ser caracterizadas e correlacionadas com base no seu conteúdo fossilífero, o que corresponde à essência da bioestratigrafia, mas os fósseis haviam permanecido subordinados ao arcabouço litoestratigráfico, de modo que as formações de composições litológicas diferentes não eram rotineiramente correlacionadas com base em fósseis similares, e as unidades estratigráficas litologicamente homogêneas não eram subdivididas apenas com base no seu conteúdo fossilífero (Schoch 1989). A compreensão de que as sucessões sedimentares podem ser subdivididas apenas com base nos seus fósseis não pode ser atribuída a um único autor, uma vez que diversos estudiosos, dentre os quais Cuvier, Deshayes, Bronn e Lyell tiveram um importante papel na elaboração e divulgação deste conceito (Hancock 1977).

A proposição de um empilhamento de assembléias fósseis independente de litofácies ${ }^{4}$, e a utilização de assembléias fósseis para a correlação global de depósitos sedimentares, foram introdu- zidas pelo naturalista francês Alcides Dessalines d'Orbigny (Hancock 1977, Schoch 1989). Sua maior contribuição foi o reconhecimento de que uma associação fossilífera poderia incluir várias unidades litoestratigráficas em um dado local, e abranger apenas uma unidade em outro, levando ao desenvolvimento do conceito de estágio (Giwa et al. 2006). Este conceito, a princípio, foi fundamentado na concepção de que destruições catastróficas da vida na Terra seriam seguidas por períodos de florescimento. Em 1850, d'Orbigny subdividiu rochas jurássicas da França em dez "zones" ou "étages", de onde se depreende que o autor empregava a palavra "zona" como sinônimo de estágio, conferindo uma conotação estratigráfica ao termo (Teichert 1958). d'Orbigny também utilizava o termo "zona" com acepção geográfica para se referir a cinturão, banda ou área mas, a partir de 1852, ele reconheceu definitivamente as zonas como subdivisões dos estágios (Hancock 1977).

$\mathrm{Na}$ década de 1830, a utilidade dos fósseis na correlação cronoestratigráfica foi reconhecida pelo geólogo alemão Friedrich August Quenstedt, que definiu as unidades tempo-rocha com base em amonóides $^{5}$ (Koutskoukos 2005). Deste modo, Quenstedt definiu a unidade fundamental da bioestratigrafia - a zona - caracterizada por uma assembléia particular de fósseis. Entretanto, a concepção moderna de zona foi estabelecida pelo estratígrafo alemão Albert Oppel (Berry 1966). Em 1856, Oppel apresentou um esquema para dividir as formações geológicas em zonas baseadas na superposição dos alcances estratigráficos de duas espécies fósseis, definindo o que atualmente é conhecido como Zona de Oppel (Hancock 1977).

Para Albert Oppel, uma zona representava o conjunto de estratos caracterizados pelo primeiro aparecimento de uma ou mais espécies, associado ao último aparecimento de outra espécie e a ocorrência conjunta de outros taxa de alcance estratigráfico mais longo. Ao discernir combinações de espécies diagnósticas com base na análise dos seus alcances estratigráficos, Oppel estabeleceu a subdivisão dos estratos em unidades hierarquicamente menores, as zonas. Posteriormente, Oppel agrupou as zonas em estágios, os estágios em séries e as séries em sistemas, demonstrando que as unidades de ordem hierárquica menor podem ser agrupadas em unidades de maior ordem (Berry 1966).

\footnotetext{
4 Conjunto de aspectos litológicos de uma unidade estratigráfica.

5 Grupo extinto de moluscos cefalópodes que desapareceu no final do Cretáceo no evento de extinção que vitimou os dinossauros.
} 
Em 1893, Sydney Buckman levantou a discussão sobre do conceito de tempo implícito nas biozonas, criando o termo "hemera" para designar o auge do desenvolvimento de uma ou mais espécies características de uma dada biozona, porém em 1902, Buckman redefiniu hemera como o tempo correspondente à deposição de uma biozona (Schoch 1989).

O início do século 20 foi marcado pela proliferação de novos termos e redefinição de termos antigos. $\mathrm{O}$ termo bioestratigrafia foi introduzido pelo paleontólogo belga Louis Dollo, em 1904, com o amplo significado de "campo de pesquisa no qual a paleontologia exerce uma forte influência sobre a geologia histórica". Da maneira como foi definida por Dollo, a bioestratigrafia deveria englobar a paleoecologia e a paleobiogeografia (Teichert 1958). Contudo, em 1910, Dollo refinou a definição do termo, passando a considerá-lo como um sinônimo da expressão "paleontologia estratigráfica". O significado moderno do termo bioestratigrafia só foi estabelecido em 1916 por Rudolf Wedekind. Segundo a definição do Guia Estratigráfico Internacional (Salvador 1994), a bioestratigrafia corresponde ao ramo da estratigrafia que trata da distribuição dos fósseis no registro estratigráfico e da organização dos estratos em unidades com base em seu conteúdo fossilífero.

\subsection{Conceitos Gerais}

As unidades bioestratigráficas são hierarquizadas, de modo que a zona bioestratigráfica ou biozona representa a unidade básica da bioestratigrafia. Uma biozona pode ser definida como um conjunto estratos caracterizado pelo seu conteúdo fossilífero, que permite distingui-lo dos estratos adjacentes. A definição de uma biozona pode ser baseada na identificação de um ou mais taxa, suas abundâncias relativas, feições morfológicas específicas de um dado grupo fóssil, ou variações em outras características relacionadas ao conteúdo e a distribuição dos fósseis nos estratos. $\mathrm{O}$ mesmo intervalo de estratos pode ser dividido de forma diferente, dependendo dos critérios diagnósticos e do grupo fóssil empregado. Segundo o Código Estratigráfico Norte-Americano (NACSN 2005), os limites laterais e verticais dos estratos que constituem uma unidade bioestratigráfica representam os limites da ocorrência dos seus elementos bióticos característicos. Os taxa que caracterizam uma biozona são conhecidos como marcadores zonais, fósseis-guia ou fósseis-índice. Para ser considerado um bom fóssil-guia, um táxon deve ter curto alcance estratigráfico, alto potencial de preservação, ampla dispersão geográfica, ser abundante e de fácil diagnose.

Os dois principais atributos de uma biozona são: (a) independência das unidades litoestratigráficas, ou seja, os limites de uma biozona podem ou não coincidir com os limites das unidades litoestratigráficas, não apresentando quaisquer relações com estes (Fig. 2); (b) independência das unidades cronoestratigráficas, uma vez que os limites da maioria das unidades bioestratigráficas são conceitualmente diácronos, devido às mudanças de fácies deposicionais, variação nas condições de fossilização, tempo de migração e diferenças biogeográficas. Assim, não se pode assumir que o limite de uma biozona tenha a mesma idade ao longo de toda a sua extensão.

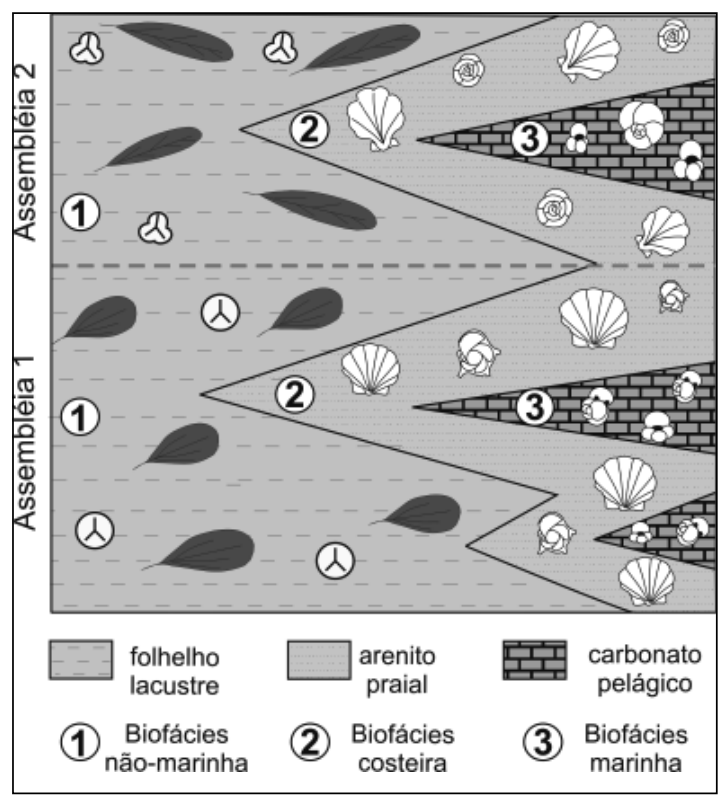

Figura 2 - Esquema ilustrativo mostrando o deslocamento lateral de biofácies (não-marinha, costeira e marinha franca) em decorrência de variações ambientais, e duas assembléias fossilíferas distintas, resultantes da sucessão dos fósseis no tempo (modificado de McGowran 2005)

De acordo com o Código Estratigráfico NorteAmericano (NACSN 2005), os limites das zonas de abundância se constituem em exceção a este princípio uma vez que refletem um evento de mortalidade em massa. Os limites laterais de uma dada biozona são definidos com base na distribuição biogeográfica dos taxa que a caracterizam, e os 
limites verticais dependem do alcance estratigráfico dos referidos taxa (Blatt et al. 1991). Como as diferentes espécies viveram durante intervalos de tempo variáveis e tiveram distribuição geográfica também variável, os limites das biozonas podem sofrer grande variação (Fig. 3). Além desse aspecto, como as unidades bioestratigráficas são baseadas na identificação de fósseis-guia, mudanças na base taxonômica podem aumentar ou reduzir o conjunto de estratos englobados em uma unidade bioestrati-

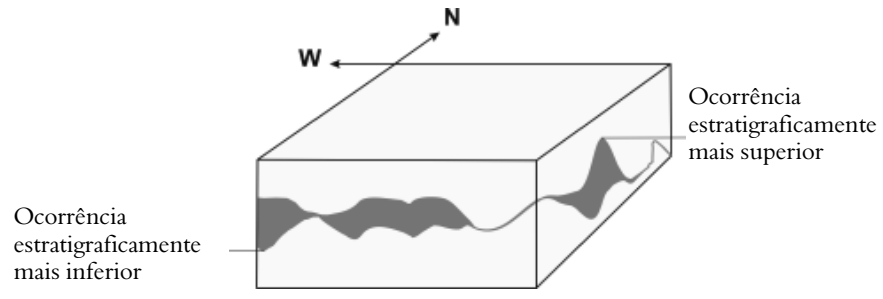

Figura 3 - Biozona hipotética indicada por seus limites geográfico e vertical. Os limites laterais são estabelecidos com base no alcance biogeográfico do táxon e os limites verticais são controlados pela persistência do táxon ao longo do tempo geológico (modificado de Blatt et al. 1991)

gráfica particular (Murphy \& Salvador, 1999).

Em relação aos limites da resolução bioestratigráfica, mesmo uma sucessão sedimentar contínua e com a total preservação do registro fóssil não permitiria a construção de zonas infinitesimalmente pequenas (Blatt et al. 1991). A resolução bioestratigráfica está diretamente relacionada à taxa de evolução das entidades taxonômicas ao longo do tempo, de modo que quanto menor a taxa de evolução de um táxon, menor será a resolução obtida através do emprego deste. Por sua vez, os grupos taxonômicos que evoluíram em altas taxas se prestam à utilização no estabelecimento de uma bioestratigrafia de alta resolução. As classes de unidades bioestratigráficas são definidas como segue:

1. Biohorizonte - Limite estratigráfico, superfície ou intervalo ao longo da qual há uma mudança significativa de caráter bioestratigráfico. Os biohorizontes apresentam grande importância para a correlação, sendo comumente utilizados como limites de biozonas, embora também possam ser reconhecidos como horizontes dentro de biozonas.

2. Zônula - O Guia Estratigráfico Internacional (Salvador 1994) desaconselha a utilização deste termo, ao qual tem sido atribuído diversos significados e, comumente, é empregado como subdivisão hierarquicamente menor que subzona.
3. Subzona - Subdivisão de uma zona.

4. Zona - Conjunto de estratos caracterizado por seu conteúdo fossilífero. Corresponde à unidade bioestratigráfica básica.

5. Superzona-Agrupamento de duas ou mais biozonas que apresentam atributos bioestratigráficos relacionados.

6. Interzona - Intervalo afossilífero situado entre duas biozonas sucessivas.

7. Intrazona - Intervalo estéril situado dentro de uma dada biozona.

\subsubsection{Tipos de unidades bioestratigráficas}

A seguir são definidos os principais tipos de biozonas reconhecidos pelo Guia Estratigráfico Internacional (Salvador 1994) e pelo Código Estratigráfico Norte-Americano (NASC 2005).

Zona de amplitude - Conjunto de estratos contidos no intervalo dos alcances estratigráfico e geográfico conhecidos de um táxon particular, ou seja, entre seus primeiro e último aparecimento globais. Os limites de uma zona de amplitude correspondem às ocorrências estratigráficas mais inferior e mais superior de um determinado táxon na seção (Fig. 4). Este tipo de biozona recebe o nome do táxon cujo alcance representa.

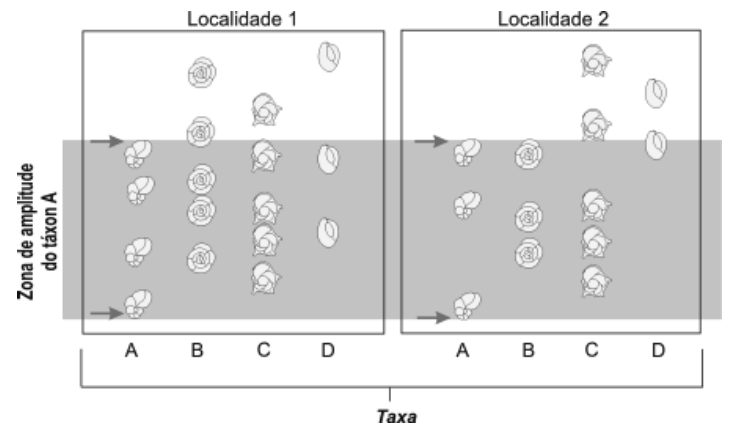

Figura 4 - Zona de amplitude. Neste exemplo os limites superior e inferior são definidos pelo alcance estratigráfico do táxon A. As setas indicam os data de aparecimento e extinção do táxon $A$

Zona de amplitude local, telizona ou topozona - Representa o conjunto de estratos correspondentes ao intervalo entre o alcance estratigráfico local de um determinado táxon. Este tipo de biozona recebe o nome do táxon cujo alcance representa. A figura 5 apresenta um exemplo de zona de amplitude local. 


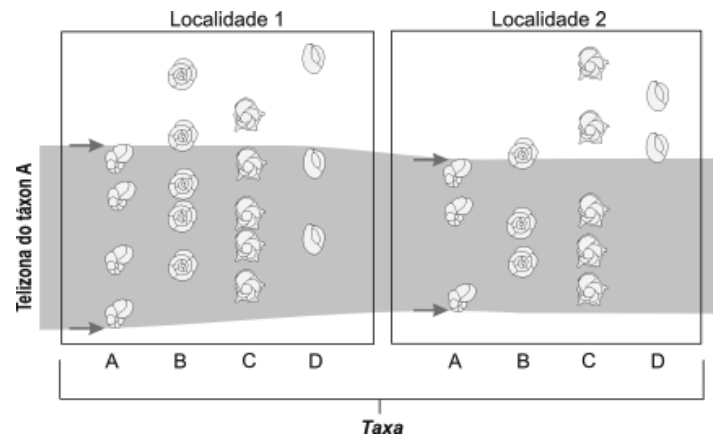

Figura 5 - Zona de amplitude local ou telizona. Este exemplo representa uma zona delimitada por biohorizontes definidos pelo alcance estratigráfico local do táxon A. As setas indicam os data de aparecimento e extinção do táxon $A$

Zona de concorrência - Conjunto de estratos que engloba a interseção dos alcances estratigráficos de dois taxa. Uma zona de concorrência pode incluir taxa adicionais, mas apenas os dois taxa especificados são utilizados para definir os limites da zona. Os limites deste tipo de biozona são marcados, em qualquer seção estratigráfica, pela ocorrência estratigráfica mais inferior do táxon com alcance mais alto, e a ocorrência estratigráfica mais superior do táxon com alcance mais baixo (Fig. 6). Por definição, todos os taxa utilizados para delimitar uma zona de concorrência devem ser evidenciados, para que um dado conjunto de estratos seja atribuído a tal zona. Este tipo de biozona recebe o nome de um ou mais taxa que a definem e caracterizam.

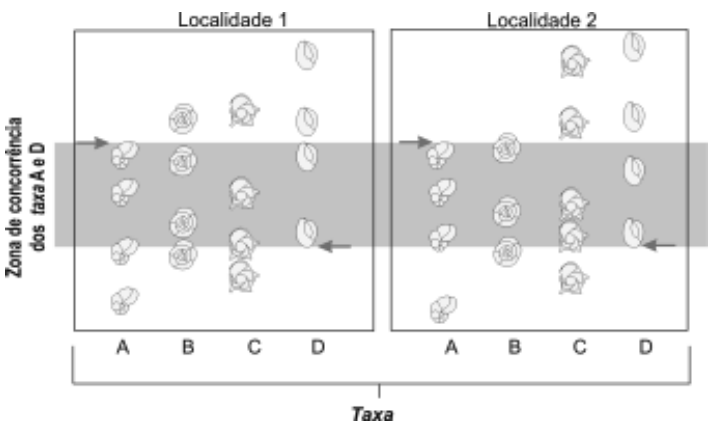

Figura 6 - Zona de concorrência. Este exemplo ilustra uma zona de concorrência caracterizada pelo alcance estratigráfico coincidente dos taxa $A$ e $D$. As setas indicam os data de aparecimento do táxon $D$ e de extinção do táxon $A$

Zona de intervalo - Conjunto de estratos entre dois biohorizontes especificados (Fig. 7). Este tipo de zona é definido e identificado com base nos seus biohorizontes limitantes, especificando-se o critério adotado na escolha destes, como a primeira e a última ocorrência consecutivas de um dado táxon. No trabalho estratigráfico de subsuperfície, onde o material paleontológico é geralmente proveniente de amostras de calha, freqüientemente contaminadas pela recirculação de sedimentos previamente perfurados e por fragmentos desmoronados das paredes do poço, as zonas de intervalo são definidas como a seção estratigráfica compreendida entre as ocorrências mais superiores (primeira ocorrência em relação ao sentido de perfuração) de dois taxa. Este tipo de zona de intervalo é conhecido como zona de última ocorrência. As zonas de intervalo recebem os nomes dos taxa que caracterizam seus biohorizontes limitantes, sendo que o nome do táxon que define o limite basal deve preceder o nome do táxon que caracteriza o limite superior.

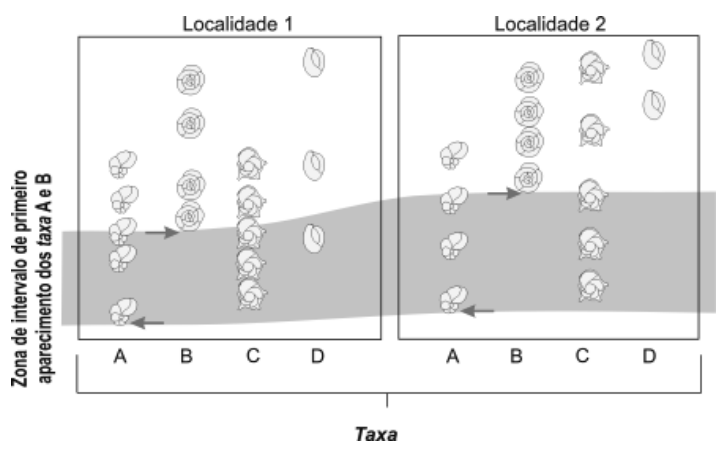

Figura 7 - Zona de intervalo. Neste exemplo, trata-se de uma zona de intervalo de primeiro aparecimento dos taxa $A$ e $B$, cujos data de primeira ocorrência se constituem nos biohorizontes que delimitam a zona

Zona de assembléia ou de associação - Corresponde ao conjunto de estratos caracterizado pela ocorrência de três ou mais taxa em uma assembléia natural, que o distingue dos estratos adjacentes. Os limites de uma zona de assembléia são os biohorizontes que marcam a ocorrência da associação que a define. Entretanto, nem todos os membros da associação necessariamente devem estar presentes para que uma determinada seção seja atribuída a uma dada zona de assembléia, e o alcance estratigráfico total de quaisquer dos taxa escolhidos como diagnósticos pode se estender além dos limites da zona (Fig. 8). Este tipo de zona recebe o nome de um dos taxa diagnósticos da assembléia fóssil.

Zona de Oppel - Esse tipo de biozona se constitui num caso especial de zona de associação. Uma zona de Oppel é definida pelo primeiro ou pelo último aparecimento de um determinado táxon associado a um táxon adicional (Fig. 9). Assim, uma zona de Oppel é quase uma zona de con- 


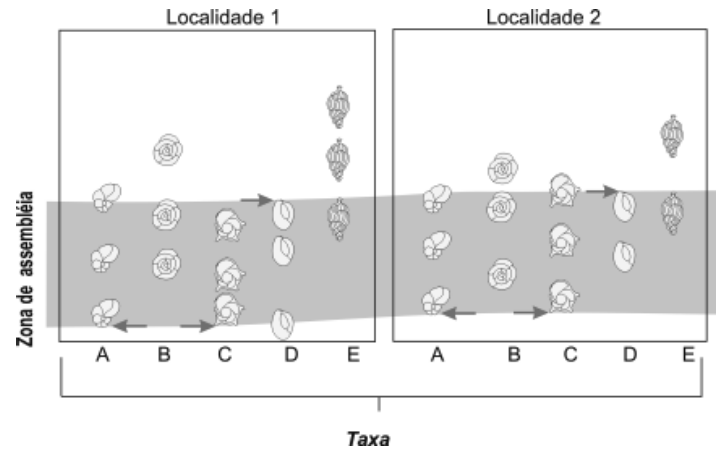

Figura 8 - Zona de assembléia. Neste exemplo a assembléia diagnóstica da zona engloba cinco taxa com diversos alcances estratigráficos. 0 limite inferior está posicionado nos data de primeiro aparecimento dos taxa $\mathrm{A}$ e $\mathrm{C}$ e o limite superior no datum de último aparecimento do táxon $E$

corrência, porém definida mais frouxamente e, portanto, é mais facilmente aplicável. Ao contrário do que ocorre com a zona de concorrência, nem todos os taxa considerados diagnósticos precisam ser identificados em uma sucessão sedimentar a fim de se reconhecer uma zona de Oppel. A zona de Oppel é nomeada com base no nome de um único táxon proeminente, embora o mesmo não necessariamente deva estar presente ao longo de toda a biozona.

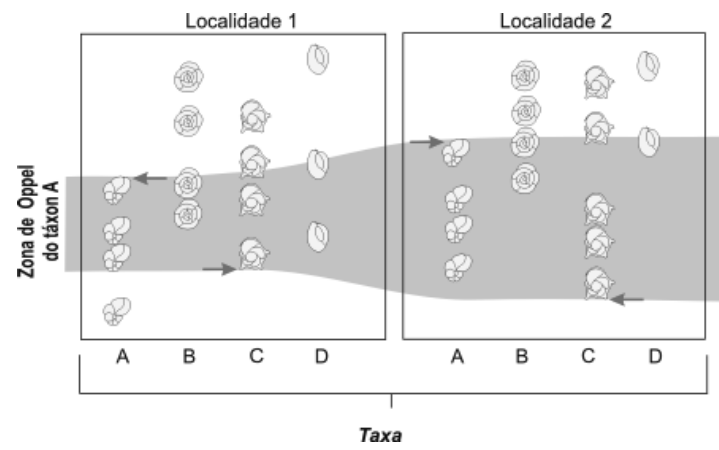

Figura 9 - Zona de Oppel. Neste exemplo a zona é caracterizada pelo datum de último aparecimento do táxon $A$ e pela ocorrência do táxon $C$

Zona de abundância, de acme ou epíbole - Conjunto de estratos nos quais a abundância de um táxon particular ou de um dado grupo de taxa é significativamente maior do que o usual ao longo da seção. A abundância incomum de um ou mais taxa no registro estratigráfico pode ser o resultado de inúmeros processos de cunho local, que podem ser repetidos em diferentes partes do mundo em diferentes épocas (Berry 1966). Assim, a zona de abundância freqüentemente tem aplicação local e está mais associada a fatores ambientais, o que não quer dizer que esta não represente um marco temporal. Os limites de uma zona de abundância correspondem aos biohorizontes ao longo dos quais é verificada uma grande variação na abundância de um ou mais taxa que caracterizam a zona (Fig. 10). De acordo com o Código Estratigráfico NorteAmericano, as biozonas baseadas em assembléias bióticas que refletem um forte controle ecológico local são incluídas no conceito de ecozona e, portanto, são informais.

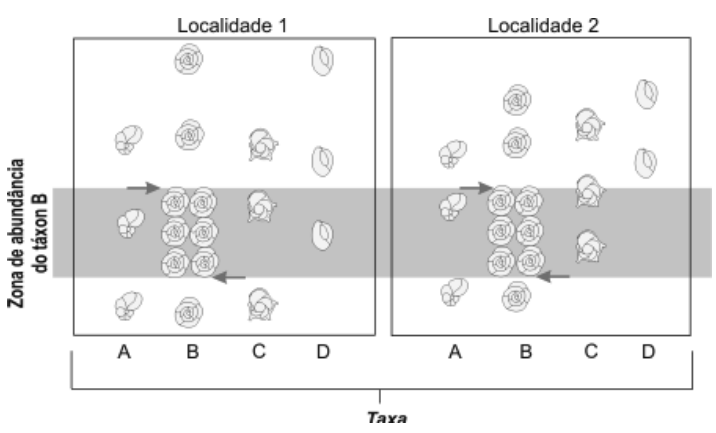

Figura 10 - Zona de abundância do táxon $B$

Zona de linhagem ou filozona - Conjunto de estratos representativo do intervalo correspondente a um segmento de uma linhagem evolutiva. Este tipo de zona pode representar o alcance total de um táxon dentro de uma linhagem, ou apenas parte do alcance de um táxon, entre o seu aparecimento e o aparecimento de seu descendente. Os limites das zonas de linhagem são determinados por biohorizontes representativos do primeiro aparecimento de sucessivos taxa em uma linhagem evolutiva (Fig. 11). As filozonas são o meio mais confiável de correlação bioestratigráfica, uma vez que seus limites são muito próximos dos limites das unidades cronoestratigráficas (Salvador 1994). Uma filozona recebe o nome do táxon cujo alcance parcial ela representa.

A escolha do tipo de zona a ser empregado no biozoneamento de uma dada área depende do tipo de material disponível para estudo. No trabalho estratigráfico de subsuperfície, a identificação taxonômica é geralmente feita com base em material recuperado de amostras de calha ${ }^{6}$, muitas

\footnotetext{
${ }^{6}$ Amostras de sedimentos obtidas a partir da perfuração de poços, onde as rochas são trituradas e, através da injeção de um líquido composto por água e substâncias minerais (lama de perfuração), são transportados para a superfície.
} 


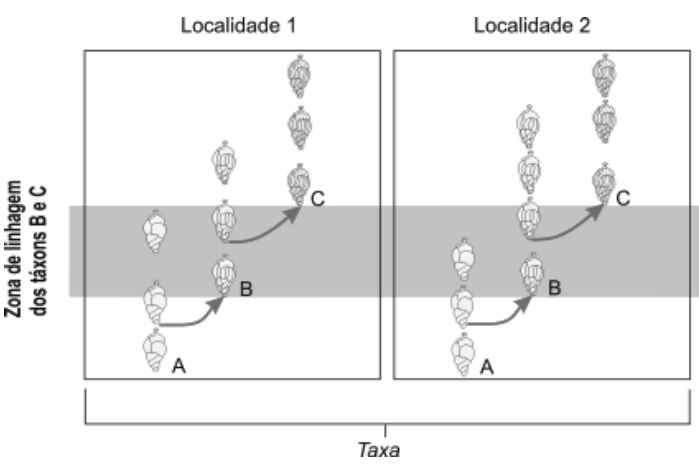

Figura 11 - Zona de linhagem ou filozona. Este exemplo ilustra a zona de linhagem delimitada pela parte do alcance estratigráfico do táxon $B$ entre o seu primeiro aparecimento e o primeiro aparecimento do táxon $C$

vezes contaminadas pela recirculação de sedimentos previamente perfurados e material desabado das paredes do poço (Murphy \& Salvador 1999). As zonas de intervalo só podem ser utilizadas no fatiamento bioestratigráfico com amostras de calha, se for empregado como critério o reconhecimento do último aparecimento do táxon. Assim, as zonas de intervalo definidas como a seção estratigráfica compreendida entre a ocorrência mais alta conhecida do fóssil (primeira ocorrência em do topo para a base) de dois taxa específicos. As zonas assim definidas são referidas como zonas diferenciais superiores, conforme designado no Artigo C.2, § 2. ${ }^{\circ}$ do Código Brasileiro de Nomenclatura Estratigráfica (Petri et al. 1986). Entretanto, de acordo com Murphy \& Salvador (1999), este tipo de biozona deve ser preferivelmente chamada de "zona de ocorrência mais alta".

Cabe observar que um arcabouço bioestratigráfico pode ser composto por diferentes tipos de zonas. Um exemplo é o esquema zonal de Bolli \& Saunders (1985) para o Oligoceno-Holoceno com base em foraminíferos planctônicos, o qual é composto por 12 zonas de intervalo, cinco telizonas, quatro zonas de concorrência e três zonas de linhagem.

\section{Foraminíferos e bioestratigrafia}

\subsection{Histórico}

Em meados do século 19, Reuss atribuiu valor estratigráfico aos foraminíferos, mas a aplicação destes organismos na bioestratigrafia teve início apenas no final do século 19 com a demanda da indústria do petróleo pela datação de seções de po- ços e comparação destas com os estratos aflorantes (Bolli et al. 1994).

A utilização dos foraminíferos para a correlação de estratos teve início com Jozef Grzybowski que iniciou seus estudos em poços de petróleo na Áustria e, após os primeiros registros sobre taxonomia dos foraminíferos, por volta de 1898, já demonstrava que estes organismos poderiam ser utilizados para a correlação de estratos em subsuperfície nos poços perfurados para a exploração de petróleo (Stainforth et al. 1975). Posteriormente Grzybowski listou espécies de foraminíferos em poços e afloramentos e destacou aquelas que poderiam ser utilizadas para caracterizar biohorizontes e, através da correlação das assembléias de foraminíferos, pôde prever reservatórios de hidrocarbonetos e identificar feições estruturais (Giwa et al. 2006).

A utilização dos foraminíferos em estratigrafia começou a ser difundida, uma vez que os diversos estágios da evolução destes organismos mostraram se constituir em uma base adequada para a subdivisão do registro sedimentar. Os principais pesquisadores a promover a utilização desta ferramenta na primeira metade do século 20 foram J. Cushman, J.J. Galloway, H. Plummer, M.P. White, R.W. Barker e W.L.F. Nuttall.

Atualmente os foraminíferos representam um dos grupos de microfósseis mais estudados nas sucessões sedimentares marinhas, desempenhando um papel muito importante tanto na indústria do petróleo quanto nos centros acadêmicos. A bioestratigrafia tem nos foraminíferos planctônicos importantes fósseis-índice que podem ser aplicados em zoneamentos detalhados, tanto no âmbito regional quanto em escala mundial (Lamb \& Beard 1972).

Devido ao seu caráter cosmopolita, os foraminíferos planctônicos atualmente são amplamente utilizados em análises biocronoestratigráficas como uma ferramenta de correlação de precisão e de datação relativa. Os foraminíferos planctônicos são especialmente úteis em bioestratigrafia, pois seu modo de vida flutuante e passivo proporciona sua rápida dispersão através de grandes distâncias nos oceanos, possibilitando uma ampla distribuição geográfica, e sua presença nos sedimentos marinhos é pouco afetada por variações faciológicas laterais (Lamb \& Beard 1972, Bolli \& Saunders 1985). Estes organismos são especialmente eficientes nas determinações de idade e na correlação de estratos, sendo aplicáveis em amplas distâncias e permitindo correlações em escala intercontinental (Bolli \& Saunders 1985). No entanto, os foraminíferos 
bentônicos foram os primeiros a serem empregados em larga escala com propósitos bioestratigráficos já na primeira metade do século 20 , uma vez que o conhecimento acerca da taxonomia e das linhagens evolutivas dos foraminíferos planctônicos ainda não estava bem fundamentado (Stainforth 1960, Bolli et al. 1994).

$\mathrm{Na}$ medida em que as perfurações avançavam para o oceano, os sedimentos se tornavam mais enriquecidos em formas planctônicas e, conseqüentemente, os foraminíferos bentônicos se tornavam mais escassos e menos eficientes na resolução de problemas de correlação. Além disso, os pesquisadores começaram a perceber que a equivalência em idade das microfaunas bentônicas se tornava pouco confiável devido a fatores ambientais que poderiam torná-las completamente distintas entre si. Assim, em diversas bacias petrolíferas importantes, as dificuldades de distinção entre questões estratigráficas e ecológicas estavam se tornando tão sérias que a solução seria se concentrar na análise dos foraminíferos planctônicos, cuja distribuição nos sedimentos é pouco afetada pelas condições ecológicas (Stainforth 1960).

Com isto, os foraminíferos planctônicos, que haviam sido inicialmente ignorados, começaram gradualmente a atrair mais atenção dos pesquisadores a partir da década de 1930, com ênfase nos sedimentos onde as formas bentônicas eram pobremente representadas (Bolli et al. 1994). A grande difusão da aplicação dos foraminíferos planctônicos para fins bioestratigráficos ocorreu a partir da década de 1950, conduzindo ao estabelecimento dos esquemas zonais atuais.

Por volta do final da década de 1950, Trinidad se tornou uma área-chave para a bioestratigrafia de foraminíferos planctônicos onde, de fato, o desenvolvimento histórico do biozoneamento de sedimentos marinhos com base nestes organismos teve início, atendendo a demandas práticas da indústria do petróleo (Lamb \& Beard 1972, Stainforth et al. 1975). Em 1957, Hans Bolli consolidou o primeiro esquema zonal com base em foraminíferos planctônicos para Trinidad. Posteriormente, as zonas por ele estabelecidas em Trinidad mostraram ter aplicação também em regiões mais distantes, e passaram a ser aceitas por diversos autores com poucas modificações, dando início à elaboração de biozoneamentos de cunho mundial (Lamb \& Beard 1972, Bermúdez \& Farias 1974).

Desde então os esquemas zonais baseados em foraminíferos planctônicos se tornaram amplamente utilizados na datação relativa das sucessões sedimentares marinhas, substituindo as tentativas iniciais com os foraminíferos bentônicos (Bolli et al. 1994). A indústria do petróleo passou a empregar a bioestratigrafia rotineiramente na datação relativa e na correlação das unidades estratigráficas. Neste contexto, os foraminíferos planctônicos desempenham um papel muito importante na resolução de problemas geológicos que vão desde a detalhada correlação poço a poço até problemas envolvendo o mapeamento regional de parâmetros paleogeográficos e paleoambientais (Stainforth et al. 1975, Giwa et al. 2006).

De acordo com Bolli et al. (1994), a partir da década de 1980 o interesse pelas formas bentônicas voltou a crescer, sendo evidente na série de conferências "Benthos" realizadas em Halifax, Canadá (1975), Pau, França (1983), Genebra, Suíça (1986) e Sendai, Japão (1990), que se seguiram às conferências "Plankton", realizadas em Genebra, Suíça (1967), Roma, Itália (1970) e Kiel, Alemanha (1974).

Paralelamente ao renascimento do entusiasmo pela aplicação bioestratigráfica dos foraminíferos bentônicos, a indústria do petróleo continuou a promover avanços na aplicação dos foraminíferos planctônicos à bioestratigrafia (Bolli et al. 1994, Giwa et al. 2006). Atualmente os foraminíferos planctônicos têm sido aplicados para fins bioestratigráficos em associação com outros grupos de microfósseis, bem como de maneira integrada com outras ferramentas, como a estratigrafia de seqüências.

Com o aumento do número de bacias classificadas como maduras para hidrocarbonetos, a investigação passou a se concentrar em escala de reservatório e, portanto, houve a necessidade de uma mudança de estratégia na aplicação das técnicas bioestratigráficas. Isto deu início à "bioestratigrafia de produção”, onde o principal foco é a caracterização e correlação de reservatórios, que figura entre os avanços mais recentes em termos de análise bioestratigráfica, ao lado da bioestratigrafia sísmica e a bioestratigrafia de seqüências (Giwa et al. 2006).

$\mathrm{O}$ apoio da indústria do petróleo tem sido de grande importância no desenvolvimento dos estudos bioestratigráficos com base em foraminíferos. No Brasil, este tipo de pesquisa tem se concentrado nas bacias sedimentares da margem continental, devido à ocorrência de importantes acumulações de óleo e gás.

Um esquema zonal com base em foraminíferos planctônicos foi proposto por Noguti \& Santos (1972) para as bacias da margem continental bra- 
sileira, contemplando a seção do Aptiano ao Mioceno. Os autores empregaram zonas de intervalo, cujos biohorizontes limitantes correspondem aos data de extinção das espécies que as nomeiam, já que a maior parte do material utilizado na elaboração deste esquema bioestratigráfico foi de amostras de calha. Posteriormente, o esquema zonal de Noguti \& Santos (1972) foi modificado por Noguti (1975), Beurlen (1982) e Viviers (1982), constituindo o único exemplo de um esquema zonal padrão com base em foraminíferos planctônicos elaborado especificamente para as bacias desta região.

Diversos autores que estudaram a bioestratigrafia da seção pré-quaternária da margem continental brasileira optaram pela aplicação do esquema zonal de Noguti \& Santos (1982), dentre os quais destacam-se Koutsoukos (1982), Martins (1984), Abreu (1990) e Mesquita (1995). Constituem-se em exceções o trabalho de Beurlen \& Regali (1987), no qual os autores propuseram biozonas informais de foraminíferos planctônicos para a seção cretácica da Bacia do Pará-Maranhão, e a aplicação do esquema biozonal de Bolli \& Saunders (1985), com base em foraminíferos planctônicos, para a seção neogênica da Bacia de Pelotas por Anjos \& Carreño (2004). Para a seção quaternária das bacias da margem continental destacam-se os trabalhos de Vicalvi (1997), Barbosa (2002), Sanjinés (2006) e Portilho-Ramos et al. (2006).

Em termos de foraminíferos bentônicos, foram realizados biozoneamentos informais, entre os quais destacam-se as propostas de Melo e Sousa et al. (2003) para a Bacia da Foz do Amazonas, de Viviers \& Abreu (1995) para as bacias da margem equatorial brasileira, e de Closs (1970), Thiesen (1977) e Fernandes (1975) para a Bacia de Pelotas.

\subsection{Limitações do zoneamento bioestratigráfico com base em foraminíferos planctônicos}

A despeito de teoricamente qualquer grupo taxonômico ter utilidade em bioestratigrafia, idealmente os taxa nectônicos e planctônicos são os preferidos para propósitos bioestratigráficos por serem mais amplamente distribuídos e, portanto, mais úteis para esta finalidade (Miall 1990).

A aplicação bem sucedida dos foraminíferos planctônicos à análise bioestratigráfica se deve ao seu rápido desenvolvimento evolutivo, que torna possível a separação de estratos com duração de menos de um milhão de anos, e de poucos centímetros de espessura (Boltovskoy 1973, Molina 2004).
A tabela 1 apresenta alguns data ${ }^{7}$ de aparecimento e extinção de foraminíferos planctônicos, considerados confiáveis e facilmente reconhecíveis, onde se verifica a possibilidade de se separar biohorizontes com resolução de até $0,03 \mathrm{Ma}$, o que corresponderia a um piscar de olhos geológico. Apesar desta vantagem, o emprego dos foraminíferos planctônicos em bioestratigrafia não se constitui em uma panacéia para todos os problemas de correlação bioestratigráfica e, como todo método, possui suas limitações.

Tabela 1 - Alguns data de foraminíferos planctônicos. $F A D=$ datum de primeiro aparecimento; $L A D$ = datum de último aparecimento (adaptado de Berggren et al 1995)

\begin{tabular}{c|c} 
Evento & Idade (Ma) \\
\hline $\begin{array}{c}\text { FAD de Globorotalia } \\
\text { tumida }\end{array}$ & 5,60 \\
\hline $\begin{array}{c}\text { LAD de Globoquadrina } \\
\text { dehicens }\end{array}$ & 5,80 \\
\hline $\begin{array}{c}\text { FAD de Sphaeroidinella } \\
\text { dehicens s.I. }\end{array}$ & 5,20 \\
\hline $\begin{array}{c}\text { LAD de Globigerinoides } \\
\text { seiglei }\end{array}$ & 4,70 \\
\hline $\begin{array}{c}\text { FAD de Globorotalia } \\
\text { puncticulata }\end{array}$ & 4,50 \\
\hline $\begin{array}{c}\text { LAD de Globorotalia } \\
\text { margaritae }\end{array}$ & 3,58 \\
\hline $\begin{array}{c}\text { FAD de Globorotalia } \\
\text { miocenica }\end{array}$ & 3,55
\end{tabular}

Entre os aspectos limitantes ao emprego destes organismos em bioestratigrafia estão a alta susceptibilidade das testas aos processos diagenéticos, a forte influência exercida pela temperatura da água na distribuição dos diferentes taxa e o fato de que as espécies representadas por indivíduos muito pequenos estão sujeitas a serem confundidos com formas jovens de outras espécies, uma vez que as feições morfológicas distintivas são imprecisas em espécimes pequenos e ainda imaturos (Stainforth et al. 1975).

\section{a. Distribuição}

Os padrões de distribuição dos foraminíferos planctônicos estão relacionados a diversos fatores, arranjados num complexo mosaico, dentre os quais estão os aspectos paleoceanográficos.

Em se tratando da aplicação bioestratigráfica dos foraminíferos planctônicos, o entendimento do contexto paleoceanográfico da região em estudo é imprescindível pois, apesar das espécies cosmopolitas habitarem simultaneamente várias províncias, a ocorrência de diversos taxa de interesse para a

\footnotetext{
${ }^{7}$ plural de datum.
} 
bioestratigrafia está diretamente associada à distribuição das massas d'água nos oceanos.

A temperatura da superfície do oceano é o fator primordial no controle da distribuição latitudinal dos organismos planctônicos modernos (Wade 1964, Spezzaferri 1995). A distribuição dos foraminíferos planctônicos é fortemente influenciada pela temperatura da água superficial e, devido à conexão existente entre os oceanos, estes organismos se distribuem muito mais uniformemente nos limites das zonas climáticas (Boltovskoy 1973).

Os foraminíferos planctônicos estão distribuídos globalmente em amplos cinturões latitudinais, que apresentam um considerável contraste na composição taxonômica (Scott 1983). O padrão de riqueza das espécies de foraminíferos planctônicos é de decréscimo do equador para os pólos (Stainforth et al. 1975, Kennett 1980, Spezzaferri 1995) (Fig. 12). Deste modo, muitos taxa estratigraficamente restritos estão confinados às massas d'água quentes, impedindo que as biozonas baseadas na ocorrência destes possam ser reconhecidas em regiões dominadas por massas d'água frias.

Um exemplo para ilustrar a restrição latitudinal de diversos taxa planctônicos de interesse bioestratigráfico é a seqüência evolutiva do Mioceno (iniciando-se pela forma mais antiga) Globorotalia fohsi peripheroronda (Banner \& Blow) $\rightarrow$ Globorotalia fohsi peripheroacuta (Banner \& Blow) $\rightarrow$ Globorotalia fohsi praefohsi (Banner) $\rightarrow$ Globorotalia fohsi fohsi (Cushman \& Ellisor), a qual se constitui em uma das séries evolutivas melhor documentadas entre os foraminíferos planctônicos. Os sucessivos membros desta série vão se tornando gradualmente mais restritos às regiões francamente tropicais, o que inviabiliza a aplicação bioestratigráfica dos membros mais jovens da referida série em regiões subtropicais e temperadas (Blow 1970).

\section{b. Efeito Elvis}

Outro fator que deve ser levado em consideração na utilização dos foraminíferos planctônicos em bioestratigrafia é que estes organismos estão sujeitos a adaptações morfológicas para a sua adequação a funções especializadas. Deste modo, a morfologia da testa é fortemente condicionada por questões biomecânicas e, conseqüentemente, vários marcadores zonais podem ser confundidos com outras espécies que ocorrem em diferentes níveis estratigráficos (Stainforth 1960). Quando duas espécies

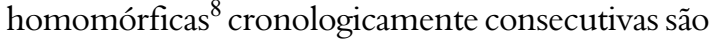
confundidas, ocorre o chamado Efeito Elvis, o qual se caracteriza quando é reportada a ocorrência de uma espécie em níveis estratigráficos acima do seu datum de extinção, como no caso das espécies de foraminíferos planctônicos Morozovella velascoensis (Cushman), Paleoceno superior até o limite Paleoceno-Eoceno, e Morozovella caucasica (Glaessner), Eoceno inferior (Arenillas 2004).

Um excelente exemplo de adaptação morfológica em foraminíferos planctônicos é a espécie Globigerinoides ruber, que se constitui em um importante marcador zonal do Mioceno. Esta espécie surgiu no Mioceno inferior e teria permanecido virtualmente inalterada até o Holoceno, exceto por uma interrupção do Mioceno médio ao Plioceno inferior (Bolli \& Saunders 1985). É possível que a forma mais jovem de Globigerinoides ruber represente o desenvolvimento de uma espécie morfologicamente muito similar à forma miocênica, porém associada a um intervalo cronoestratigráfico distinto.

De fato, Cordey (1967) classificou a forma miocênica de Globigerinoides ruber em uma espécie separada (Globigerinoides subquadratus) e sugeriu que esta poderia ser distinguida da forma pliocênica com base em análises ontogenéticas ${ }^{9}$ e filogenéticas ${ }^{10}$, embora não tenha encontrado diferenças morfológicas externas entre ambas. Entretanto, Stainforth et al. (1975) sugerem a utilização do nome Globigerinoides ruber também para as formas miocênicas, embora a manu-

Figura 12 - Relação entre biozona, biocronozona e a distribuição latitudinal dos organismos. 0 invólucro tempo-latitude descreve a biozona é fortemente simétrico pois as flutuações climáticas e de massas água é bipolar (modificado de McGowran 2005)
${ }^{8}$ Organismos distintos que apresentam semelhanças morfológicas como resultado de convergência adaptativa.

${ }^{9}$ Referente a ontogenia, ou conjunto de processos que ocorrem ao longo do desenvolvimento de um organismo.

${ }^{10}$ Referente a filogenia, ou história evolutiva dos organismos. 
tenção de dois nomes pudesse facilitar a distinção entre as formas com alcances estratigráficos diferentes. A espécie Globigerinoides ruber também pode ser utilizada para ilustrar a variação de caracteres morfológicos causada por mudanças ambientais uma vez que, segundo Yassini \& Jones (1995), o tamanho das aberturas nesta espécie varia com a temperatura, apresentando aberturas menores em períodos glaciais.

Para proceder à correta distinção entre formas homomórficas deve-se levar em consideração a assembléia associada a estas. A figura 13 ilustra espécimes de Globigerinoides ruber identificados na porção sul da margem continental brasileira.

\section{c. Fatores tafonômicos}

Devido ao seu pequeno tamanho, os microfósseis apresentam diversas particularidades em termos de tafonomia. A dissolução se constitui em um dos principais fatores que afetam os microfós-

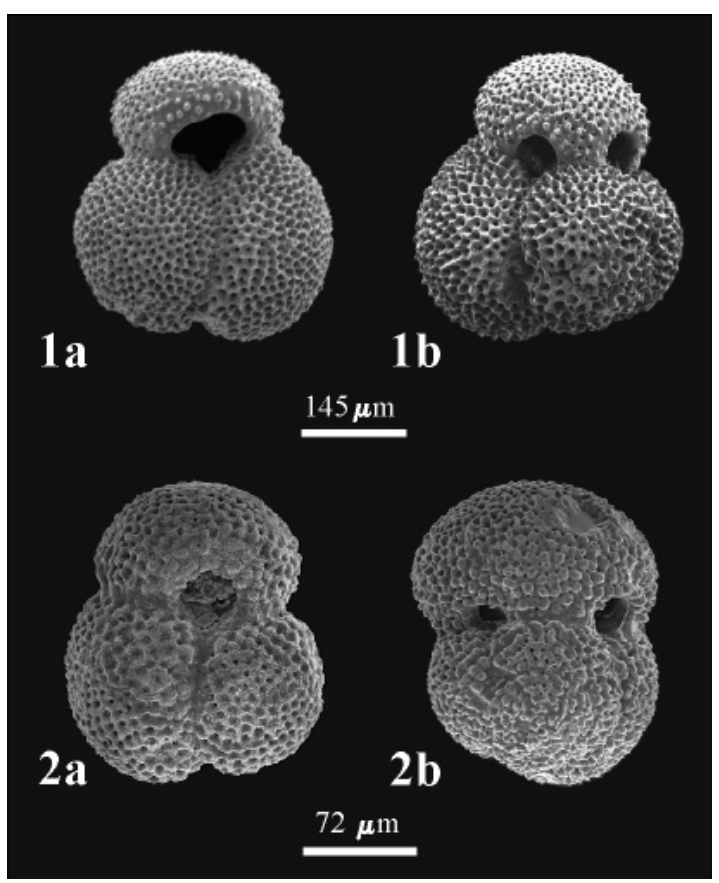

Figura 13 - Exemplares de Globigerinoides ruber provenientes da margem continental sul-brasileira. (1) espécime pliocênico; (2) espécime miocênico, (a- vista umbilical, 2- vista lateral). Observar que a posição das aberturas e o arranjo das câmaras são idênticos

seis de parede calcária, já que a sua preservação é afetada pela solubilidade do carbonato de cálcio e, conseqüentemente, causa grandes perdas no registro microfossilífero já que seu tamanho reduzido proporciona uma dissolução mais rápida e muitas vezes completa. A solubilidade do carbonato de cálcio depende de vários fatores dentre os quais a saturação do íon $\mathrm{CO}^{-2}$, temperatura, concentração de $\mathrm{CO}_{2}$ e pressão hidrostática (Molina 2004).

Ainda que a maioria das espécies de foraminíferos planctônicos passe a maior parte de sua vida na zona epipelágica, muitas espécies preferem habitar as águas mais profundas, às quais descem depois de transcorrido o período de vida juvenil. Esta mudança de habitat se deve a mudanças morfológicas da testa, dentre as quais a mais importante é a formação de uma camada suplementar de calcita, o córtex, que aumenta o peso específico da mesma (Boltovskoy 1973).

Alterações morfológicas como as acima mencionadas fazem com que a biocenose ${ }^{11} \mathrm{da}$ camada superficial do oceano seja distinta da tanatocenose $\mathrm{e}^{12}$ do fundo. Esta diferença aumenta com o tempo devido ao fenômeno de dissolução das testas, que ocorre logo após a morte dos organismos (Boltovskoy 1971 apud Boltovskoy 1973). A figura 14 ilustra diversos processos que atuam na alteração do registro estratigráfico da biocenose dos microfósseis planctônicos, dentre os quais a fragmentação, o transporte, a dissolução, o retrabalhamento e as diferenças sazonais na produtividade.

A dissolução geralmente tem caráter seletivo, afetando alguns taxa e não a outros, o que pode causar o desaparecimento aparente de um ou mais taxa mais susceptíveis (Stainforth et al. 1975, Arenillas 2004). A ordem de dissolução dos foraminíferos planctônicos está diretamente relacionada ao habitat original das espécies. As espécies que habitam as águas mais quentes, e possivelmente aquelas que vivem nas águas superficiais, se dissolvem primeiro, enquanto as que habitam águas mais frias e profundas são mais resistentes (Spezzaferri 1995). Além disso, os microfósseis de parede aragontítica são mais susceptíveis à dissolução, a não ser que tenham sofrido neomorfismo ${ }^{13}$ para calcita, que é mais estável (Molina 2004).

A susceptibilidade à dissolução tem sido associada com a morfologia da testa, de modo que os taxa que apresentam parede densamente perfurada, com poros grandes, dentre os quais estão incluídas várias espécies do gênero Globigerinoides,

\footnotetext{
${ }^{11}$ Conjunto de populações de diferentes espécies.

12 Restos acumulados de organismos de uma ou mais biocenoses.

13 Processo de transformação, sob condições de soterramento, de uma espécie mineral em outra cuja composição é a mesma, mas as estruturas cristalinas são diferentes. No caso da calcita e da aragonita ambos são compostos por carbonato de cálcio, porém com diferentes estruturas cristalinas.
} 


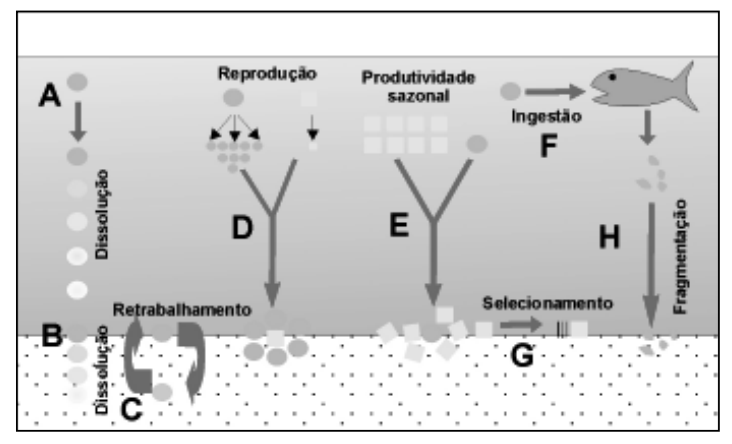

Figura 14 - Diagrama esquemático ilustrando os diversos mecanismos que alteram o registro estratigráfico dos microfósseis planctônicos (modificado de http://biolo.bg.fcen.uba.ar/brasil. htm)

são os primeiros a sofrer dissolução (Stainforth et al. 1975). Os taxa mais resistentes à dissolução tendem a apresentar testas compactas, de paredes espessas, entre os quais destacam-se as espécies dos gêneros Sphaeroidinella e Sphaeroidinellopsis. A figura 15 mostra duas espécies com diferentes suscetibilidades à dissolução, Sphaeroidinellopsis seminulina, com paredes espessas e recobertas por córtex e Globigerinoides trilobus immaturus, com paredes finamente perfuradas, ambas identificadas nos estratos neogênicos da Bacia de Pelotas, margem continental sul-brasileira.

\section{d. Fatores paleoecológicos}

Entre diversos fatores que dificultam a utilização dos foraminíferos planctônicos em bioestratigrafia está o chamado Efeito Lázaro, que representa o resultado de uma mudança paleoambiental, geralmente brusca, que provoca desaparecimentos locais (pseudoextinções) de uma ou mais espécie seguidos por novas colonizações (Molina 2004). A conseqüência é o desaparecimento temporário de uma ou mais espécies em uma área geográfica e o seu reaparecimento em um intervalo de tempo posterior, o que provoca a distribuições estratigráficas descontínuas.

Há diversos casos de taxa cuja distribuição estratigráfica nas seções de uma bacia ou província é interrompida devido a mudanças ambientais que fizeram com que o paleoambiente não fosse favorável a estas espécies em determinados níveis estratigráficos. Um exemplo típico decorre dos processos de transgressão-regressão ou de mudanças cíclicas na salinidade em uma determinada região ou província, quando os fatores paleoecológicos mudam temporariamente. Deste modo, os taxa mais sensíveis (conhecidos como taxa-Lázaro) são momentaneamente substituídos por outros mais

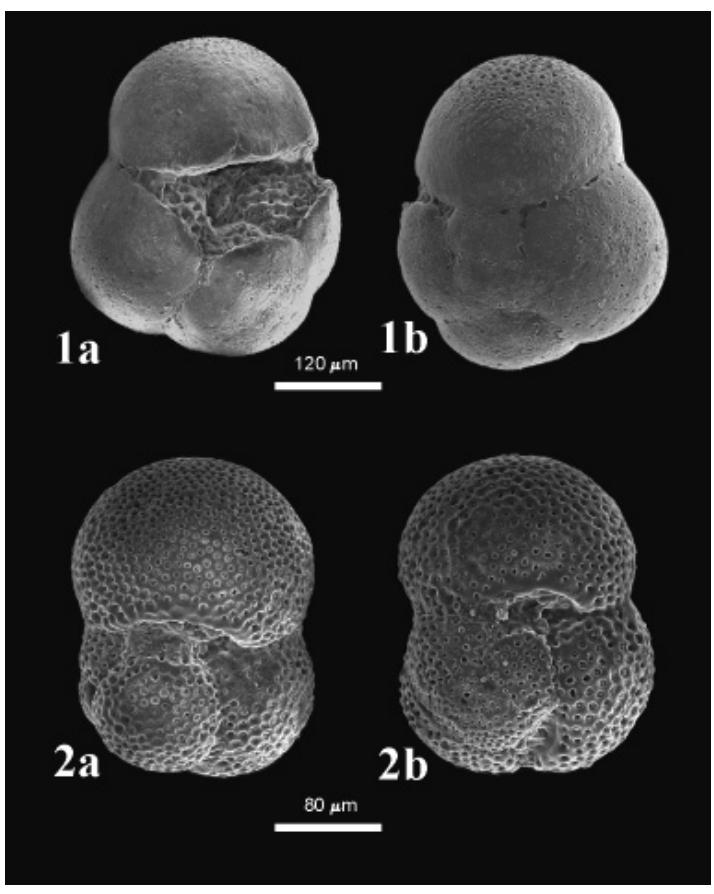

Figura 15- Espécies planctônicas com diferentes suscetibilidades à dissolução. (1) Sphaeroidinellopsis seminulina; (2) Globigerinoides trilobus immaturus. (avista umbilical, b-vista lateral). Exemplares provenientes da bacia de Pelotas

tolerantes às mudanças dos parâmetros ambientais (Arenillas 2004).

Se os taxa-Lázaro são utilizados como fósseisguia, provocam grandes equívocos e datações relativas incoerentes. Portanto, os fatores paleoecológicos devem ser levados em consideração nos estudos bioestratigráficos, uma vez que não causam apenas o Efeito Lázaro mas também o diacronismo ${ }^{14}$ ao longo dos limites bioestratigráficos.

\section{Abordagem didática}

A literatura sobre bioestratigrafia e foraminíferos está concentrada principalmente em artigos científicos e textos destinados a um público especializado. O número de publicações que enfocam estes temas de maneira didática e acessível aos estudantes ainda é reduzido, sobretudo em língua portuguesa. Assim, além de apresentar os aspectos históricos e a base conceitual da bioestratigrafia e da utilização dos foraminíferos na aplicação desta ferramenta, são sugeridos a seguir alguns exercícios para a fixação e aplicação dos conceitos apresentados.

\footnotetext{
14 Referente a diácrono, ou seja, que não é simultâeneo.
} 
1) A determinação de idade das rochas sedimentares é necessária para:

i. ( ) Cálculo das taxas de sedimentação;

ii. ( ) Determinação de paleoambientes;

iii.( ) Calibração dos registros paleomagnéticos;

iv. ( ) Correlação entre rochas aflorantes em localidades distintas;

2) As características de um táxon útil em bioestratigrafia são:

i. ( ) Alto potencial de preservação, alcance estratigráfico longo e lenta dispersão geográfica;

ii. ( ) Restrição ambiental, curto alcance estratigráfico e fácil reconhecimento;

iii. ( ) Dispersão geográfica ampla, fácil reconhecimento e alto potencial de preservação;

3) Suponha que você dispõe de um testemunho de sedimentos de águas marinhas profundas que já foi descrito em termos de fácies sedimentares. Qual o próximo passo para se proceder do estudo deste material tendo em vista que o objetivo é correlacionar estas fácies com aquelas descritas na porção mais rasa da bacia?

4) Com base em foraminíferos planctônicos não seria possível realizar estudos bioestratigráficos nas seguintes sucessões sedimentares:

i. ( ) Turbiditos Mioceno inferior;

ii. ( ) Folhelhos marinhos do Permiano inferior;

iii. ( ) Carbonatos do Cretáceo superior;

iv. ( ) Siltitos do Jurássico superior;

v. ( ) Folhelhos lacustres do Plioceno superior;

4.1) Justifique:

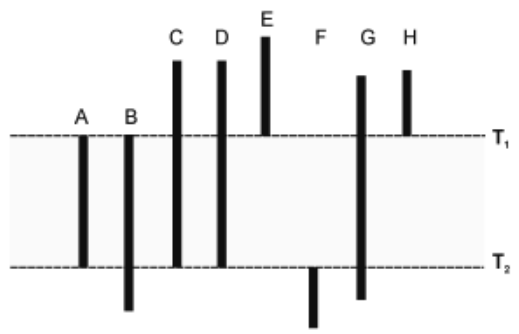

Figura 16
5) Que tipo de biozona pode ser estabelecida no intervalo assinalado da seção (Fig. 16), utilizando-se:
i. O táxon $\mathrm{A}$.
ii. Os taxa B e C.
iii. Os taxa E e G.

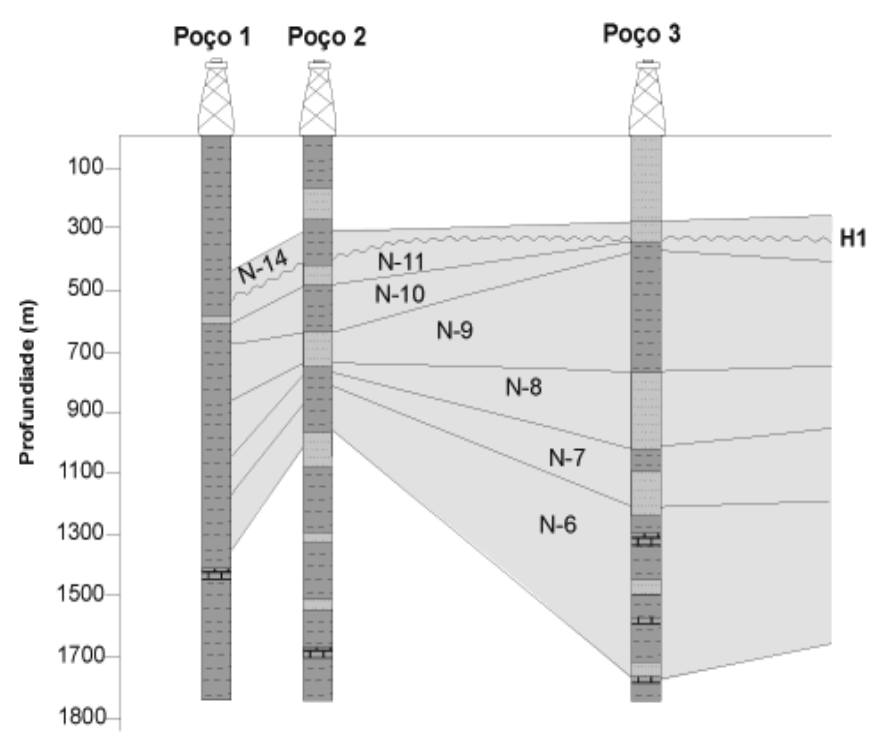

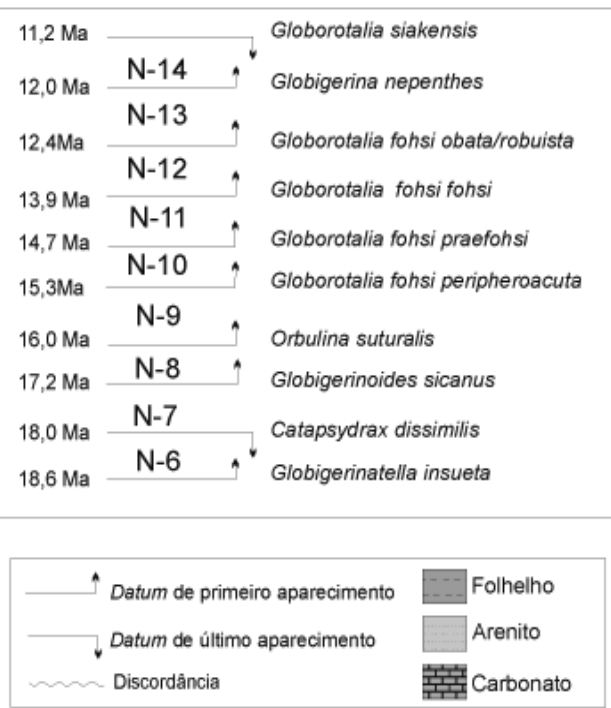

Figura 17

6) Na Figura 17 é mostrado o fatiamento bioestratigráfico para o intervalo de tempo entre 18,6 e 11,2 Ma em uma sucessão sedimentar hipotética com base no esquema zonal de Blow (1969) e os data de aparecimento e extinção das espécies de foraminíferos planctônicos que delimitam as zonas segundo 


\section{Berggren \& Van Couvering (1974) e Saito (1977) apud Kennett \& Srinivasan (1983). De acordo com as informações apresentadas na figura:}

i. Identifique os tipos de biozona utilizados no biozoneamento com base nos bioeventos que os caracterizam.

ii. Calcule a taxa de sedimentação $(\mathrm{m} / \mathrm{Ma})$ do pacote de arenito englobado na biozona $\mathrm{N}-8$ no poço 3 e do pacote de folhelho que corresponde à deposição durante a zona N-10 no poço 2 .

iii. Quanto tempo está envolvido no hiato representado pela discordância H1?

\section{RESPOSTAS}

1) i. ( V); ii. ( F ); iii. ( V ); iv. (V)

2) item iii.

3) verificar a ocorrência de microfósseis nestes sedimentos e caso estejam presentes, realizar o estudo bioestratigráfico visando determinar a idade relativa da seção em estudo. Assim será possível contextualizar estes sedimentos no tempo.

4) itens ii. e v.

4.1) ii. Os foraminíferos planctônicos surgiram no final do Triásico.

v. Os foraminíferos planctônicos são exclusivamente marinhos.

5) i. Zona de amplitude do táxon A; ii. Zona de concorrência dos taxa B e C; iii. Zona de intervalo.

6)i. Zonas de intervalo: N-6, N-7, N-8, N-9, N-13 e N-14; zonas de linhagem: N-10, N-11 e N-12.

ii. duração da zona N-8 = 1,2 Ma.

espessura de depósitos correspondentes à N-8 na área do poço $3=300 \mathrm{~m}$.

taxa de sedimentação $=250 \mathrm{~m} / \mathrm{Ma}$.

duração da zona $\mathrm{N}-10=0,6 \mathrm{Ma}$;

espessura de depósitos correspondentes à N-10 na área do poço $2=133,3 \mathrm{~m}$.

taxa de sedimentação $=222,2 \mathrm{~m} / \mathrm{Ma}$.

iii. no mínimo 1,9 Ma.

\section{Agradecimentos}

As autoras agradecem a G. Fauth (UNISINOS) pelo incentivo à publicação deste artigo, a $\mathrm{H}$. Zerfass (CPRM) pela leitura crítica do manuscrito e a C. Bergue (UNISINOS) e um revisor anônimo pelas valiosas sugestões. G.S. Anjos-Zerfass agradece a ANP pela bolsa de estudos e ao Programa de PósGraduação em Geociências da UFRGS/ PRH-12 pela infra-estrutura. E.J. Andrade agradece ao $\mathrm{CNPq}$ pela bolsa de Pós-Doutorado (N ${ }^{\circ} 151656 / 20053$ ) no curso de Pós-Graduação em Geologia da UFBA.

\section{Referências bibliográficas}

Abreu V. S. 1990. Bioestratigrafia do Terciário da Bacia de Campos, com base em foraminíferos planctônicos. Programa de Pós-Graduação em Geociências, Porto Alegre, Universidade Federal do Rio Grande do Sul, Dissert. Mestr., 235p.

Anjos G. S. \& Carreño, A.L. 2004. Bioestratigrafia (Foraminiferida) da sondagem 1-SCS-3B, Plataforma de Florianópolis, Bacia de Pelotas. Rev. Bras. de Paleont., 7(2):127-138.

Arenillas I. 2004. Bioestratigrafía: Limitaciones y ventajas de los microfósiles. In: E. Molina (ed.). 2004. Micropaleontología. Zaragoza, Prensas Universitárias de Zaragoza, p.571-590.

Barbosa V.P. 2002. Sistemática, bioestratigrafia e paleoceanografia de foraminiferos do Quaternário do talude continental das bacias de Santos e Campos. Programa de Pós-Graduação em Geologia, Universidade Federal do Rio de Janeiro, Tese Dout., 455p.

Berggren W.A. \& Van Couvering J.A. 1974. The late Neogene: biostratigraphy, geochronology and paleoclimatology of the last 15 million years in marine and continental sequences. Palaeogeography, Palaeoclimatology, Palaeoecology, 16(1-2):1-126.

Berggren W.A., Hilgen F.J., Langereis C.G., Kent D.V., Obradovich J.D., Raffi I., Rayamo M.E. \& Shackleton, N.J. 1995. Late Neogene Chronology: New perspectives in high-resolution stratigraphy. Geological Society of America Bulletin, 107(11):1272-1287.

Bermúdez P., Farias J.R. 1974. Bioestratigrafia Venezoelana - Zonación del Cenozóico al Reciente basada en el estudio de los foraminíferos planctónicos. Revista Española de Micropaleontología, 9(2):159-189.

Berry W.B.N. 1966. Zones and zones - with exemplification from the Ordovician. Bulletin of the American Association of Petroleum Geologists, 50(7):1487-1500.

Beurlen G. 1982. Bioestratigrafia e geohistória da 
seção marinha da margem continental brasileira. Boletim Técnico da Petrobras, 25(2):77-83.

Beurlen G. \& Regali M.S.P. 1987. O Cretáceo da Plataforma continental do Maranhão e Pará, Brasil: bioestratigrafia e evolução paleoambiental. Boletim de Geociências da Petrobrás, 1(2):135-155.

Blatt H., Berry, W.B.N., Brande S. 1991. Principles of stratigraphic analysis. Boston, Blackwell Scientific Publications, $512 \mathrm{p}$.

Blow W.H 1969. Late Middle Eocene to recent Planktonic Foraminiferal Biostratigraphy. In: P. Brönnimann \& H.H. Renz (eds.). 1969. International Conference on Planktonic Microfossils, 1, 1967. Proceedings, Geneva, v. 1, p. 199-422.

Blow W.H. 1970. Validity of biostratigraphic correlations based on the Globigerinacea. Micropaleontology, 16(3):257-268.

Bolli H.M., Saunders J.B. 1985. Oligocene to Holocene low latitude planktic foraminifera. In: H.M. Bolli J.B. Saunders \& K. Perch-Nielsen (eds.). 1985. Plankton Stratigraphy. Cambridge, Cambridge University Press, p. 155-262.

Bolli H.M, Beckman, J.P., Saunders, J.B. 1994. Benthic foraminiferal biostratigraphy of the south Caribbean region. Cambridge, Cambridge University Press, 408 p.

Boltovskoy E. 1965. Los Foraminiferos Recientes. Eudeba: Buenos Aires. 510p.

Boltovskoy E. 1973. Estudio de testigos submarinos del Atlántico Sudoccidental. Revista del Museo Argentino de Ciencias Naturales Bernardino Rivadavia (Geología), 7(4):340 p.

Closs D. 1970. Estratigrafia da Bacia de Pelotas, Rio Grande do Sul. Iheringia, 1:3-76.

Cordey W.G. 1967. The development of Globigerinoides ruber (d'Orbigny 1839) from Miocene to Recent. Palaeontology, 10(4):647-659.

Giwa G.O., Oyden A.C., Oksun E.A. 2006. Advances in the application of biostratigraphy to petroleum exploration and production. In: Search and Discovery Article \#50029(2006). <www.searchanddiscovery.com/documents/2006/06002giwa/index. htm > Data do último acesso: 12 de fevereiro de 2007.

Fernandes J.M.G. 1975. O gênero Uvigerina (Foraminiferida) do Cenozóico superior na Bacia de Pelotas, Rio Grande do Sul, Brasil. Curso de Pós-Graduação em Geociências, Porto Alegre, Universidade Federal do Rio Grande do Sul, Dissert. Mestr., 121 p.

Gooday A.J., Levin L.A., Linke P., Heecker B. 1992. The distribution and ecology of Bathysiphon filiformis Sars and B. major de Folin (Protista, Foraminiferida) on the continental slope off North Caroli- na. Journal of Foraminiferal Research, 22:129-146.

Hancock J.M. 1977. The historic development of biostratigraphic correlation. In: E.G. Kauffman \& J.E Hazel (eds.). 1977. Concepts and methods of biostratigraphy. Stroudsburg, Hutchinson \& Ross, p. 3-22.

Kennett J.P. 1980. Paleoceanographic and biogeographic evolution of southern ocean during the Cenozoic and Cenozoic microfossils datums. Palaeogeography, Paleoclimatology, Palaeoecology, 31:123-152.

Kennett J.P. \& Srinivasan, S. 1983. Neogene planktonic foraminifera. Stroudsburg, Hutchinson Ross Publishing Company, 265p.

Koutsoukos E.A.M. 1982. Geohistória e paleoecologia das bacias marginais de Florianópolis e Santos. In: Congr. Bras. Geol., 32, 1982. Anais, Salvador, SBG, v. 5, p. 2369-2382.

Koutsoukos E.A.M. 2005. Stratigraphy: Evolution of a concept. In: E.A.M. Koutsoukos (ed.). 2005. Applied stratigraphy. Netherlands, Springer, p. 3-19.

Lamb J.L., Beard J.H. 1972. Late Neogene planktonic foraminifers in the Caribbean, Gulf of Mexico and Italian stratotypes. The University of Kansas Paleontological Contributions, 57:1-67.

Lipps J.H. 1981. What, if anything, is micropaleontology? Paleobiology, 7(2):167-199.

Lipps J.H. \& Rozanov A.Y. 1996. The late Precambrian-Cambrian agglutinated fossil Platysolenites. Paleontological Journal, 30:345-357.

Loeblich A.R., Tappan H. 1988. Foraminiferal genera and their classification. New York, Van Nostrand Reinhold Company, 2 v., 970p.

Loeblich A.R. , Tappan H. 1992. Present status of foraminiferal classification, in: Studies in Benthic Foraminifera (eds Y. Takayanagi and T. Saito), Proceedings of the Fourth International Symposium on Benthic Foraminifera, Sendai, 1990 (Benthos 90). Tokai University Press, Tokyo, Japan, p. 93-102.

Martins J.M.G.F. 1984. Paleoecologia e bioestratigrafia (Foraminiferida) da Formação Pirabas, Estado do Pará. Programa de Pós-Graduação em Geociências, Porto Alegre, Universidade Federal do Rio Grande do Sul, Tese Dout., 284p.

McGowran B. 2005. Biostratigraphy - Microfossils and Geological Time. Cambridge, Cambridge University Press, 424p.

Mello e Sousa S. H., Fairchild T. R. \& Tibana P. 2003. Cenozoic biostratigraphy of larger foraminifera from the Foz do Amazonas Basin, Brazil. Micropaleontology, 49(3):253-266.

Mesquita A.C.F. 1995. Microbioestratigrafia do Terciário 
da bacia de Santos, com base em foraminíferos planctônicos. Programa de Pós-Graduação em Geociências, Porto Alegre, Universidade Federal do Rio Grande do Sul, Dissert. Mestr., 167p.

Miall A.D. 1990. Principles of sedimentary basin analysis. 2.ed. New York, Springer, 668 p.

Molina E. 2004. Micropaleontología, Concepto, historia y estado actual. In: E. Molina (ed.). 2004. Micropaleontología. Zaragoza, Prensas Universitárias de Zaragoza, p. 13-33.

Murphy M.A. \& Salvador A. 1999. International stratigraphic guide: An abridged version. Episodes, 22:255-271.

NACSN (North American Commission on Stratigraphic Nomenclature). 2005. North American Stratigraphic Code. American Association of Petroleum Geologists Bulletin, 89(11):1547-1591.

Noguti I. 1975. Zonación bioestratigráfica de los foraminíferos del Terciário de Brasil. Revista Española de Micropaleontologia, 7(3):391-401.

Noguti I. \& Santos J.F. 1972. Zoneamento preliminar por foraminíferos planctônicos do Aptiano ao Mioceno na plataforma continental do Brasil. Boletim Técnico da Petrobras, 15(3):265-283.

Pawlowski J., Holzmann M., Berney C., Fahrni J., Gooday A.. J., Cedhagen T., Habura A. and Bowser S.S. 2003. The Evolution of Early Foraminifera. Proceedings of the National Academy of Sciences of the United States of America, 100(20):1149411498.

Petri S., Coimbra A.M., Amaral G., Ojeda y Ojeda H., Fúlfaro V.J., Ponçano W.L. 1986. Código Brasileiro de Nomenclatura Estratigráfica. Rev. Bras. Geoc., 16(4):372-376.

Portilho-Ramos R.C., Rio-Netto A.M. \& Barbosa C.F. 2006. Caracterização bioestratigráfica do Neógeno superior da Bacia de Santos com base em foraminíferos planctônicos. Rev. Bras. Paleont., 9(3):349-354.

Salvador A. 1994. International stratigraphic guide. 2.ed. Boulder, Geological Society of America. 314p.

Sanjinés A.E.S. 2006. Biocronoestratigrafia de foraminíferos em três testemunhos do Pleistoceno-Holoceno do talude continental da Bacia de Campos, RJ-Brasil. Programa de Pós-Graduação em Geologia, Universidade Federal do Rio de Janeiro, Dissert. Mestr., 119p.

Seyve C. 1990. Introdução à micropaleontologia. Angola, Elf Aquitaine Angola, 231p.

Schoch R.M. 1989. Stratigraphy: Principles and Methods. New York, Van Nostrand Reinhold, 375p.

Scott G.H. 1983. Biostratigraphy and histories of up- per Miocene-Pliocene Globorotalia, South Atlantic and South West Pacific. Marine Micropaleontology, 7:369-383.

Sen Gupta B.K. 1999. Systematics of Modern Foraminifera. In: B.K. Sen Gupta (ed.). 1999. Modern Foraminifera. Kluwer Academic Publishers, p. 7-36.

Spezzaferri S. 1995. Planktonic foraminiferal implications across the Oligocene-Miocene Transition in the oceanic record (Atlantic, Indian and South Pacific). Palaeogeography, Palaeoclimatology, Palaeoecology, 114:48-74.

Stainforth R.M. 1960. Current status of transatlantic Oligo-miocene correlation by means of planktonic foraminifera. Revue de Micropaléontologie, 2(4):219-230.

Stainforth R.M., Lamb J.L., Luterbacher H., Beard J.H., Jeffords R.M. 1975. Cenozoic planktonic foraminiferal zonation and characteristics of index forms. The University of Kansas Paleontological Contributions, 62:1-425.

Teichert C. 1958. Some biostratigraphical concepts. Geological Society of America Bulletin, 69:99-120.

Thiesen Z.V. 1977. Bolivinitidae e Caucasinidae (Foraminiferida) do Cenozóico superior da bacia de Pelotas, Rio Grande do Sul. Acta Geológica Leopoldensia, 2(3):8-32.

Universidad de Buenos Aires. Formation and deformation of the microfossil record: Plankton, sediment traps and surface sediments < de http://biolo.bg.fcen.uba. ar/brasil.htm > . acesso: 30 março 2007.

Wade M. 1964. Application of the lineage concept to biostratigraphic zoning based on planktonic foraminifera. Micropaleontology, 10(3):273-290.

Yassini I., Jones, B.G. 1995. Foraminifera and ostracoda from estuarine and shelf environments on the southeastern coast of Australia. Wollongong, University of Wollongong Press, 484 p.

Vicalvi M.A. 1997. Zoneamento bioestratigráfico e paleoclimático dos sedimentos do Quaternário superior do talude da Bacia de Campos, RJ, Brasil. Boletim de Geociências da Petrobras, 11(1/2):132165.

Viviers M.C. 1982. Biocronoestratigrafia da Bacia do Ceará. In: Congr. Bras. de Geol., 32, 1982. Anais, Salvador, SBG, v. 5, p.2433-2449.

Viviers M.C. \& Abreu W.S. 1995. Os macroforaminíferos nas bacias da margem equatorial brasileira: Uma contribuição a bioestratigrafia do Neógeno. Resumo das comunições, An. da Acad. brasil. Ciênc., 67(3):393. 